\title{
Maintaining Cultural Identity in Translated Literary Texts: Strategies of Translating Culture-Specific Items in two Arabic plays
}

\author{
Samar Zahrawi \\ Department of World Languages and Cultures \\ College of Humanities and Social Sciences \\ Sam Houston State University, Huntsville, TX, USA.
}

\begin{abstract}
This article focusses on the translator's task as a cultural mediator who has to transfer the nuances of the literary text faithfully. The translation of culture-specific items, such as proverbs, figurative language, reference to religion, mythology or literature, and stylistics, are at the core of the discussion. This paper discusses generally recommended strategies used in translating culture specific items (CSIs), and further analyses and evaluates such strategies as used in two translated Arabic plays; Sa'dallah Wannous's The Glass Café (1978/2004) and Mamdouh 'Udwan's Reflections of a Garbage Collector (1987/2006). The translation strategies used in these two plays are recognized and rationalized in terms of giving a domesticated or a foreignized effect. Besides transferring meaning, the cultural identity of the text is highlighted as a mainstay of the translation process
\end{abstract}

Key words: Translation of culture specific items, translating religious language, translation strategies, translating stylistics

Cite as: Zahrawi, S. (2018). Maintaining Cultural Identity in Translated Literary Texts: Strategies of Translating Culture-Specific Items in two Arabic plays. Arab World English Journal for Translation \& Literary Studies, 2 (2).

DOI: http://dx.doi.org/10.24093/awejtls/vol2no2.1 